\title{
UMA VISÃO SOBRE A ESTRUTURA, COMPOSIÇÃO E BIODEGRADAÇÃO DA MADEIRA
}

\author{
Walter Carvalho*, Larissa Canilha, André Ferraz e Adriane Maria Ferreira Milagres
}

Departamento de Biotecnologia, Escola de Engenharia de Lorena, Universidade de São Paulo, CP 116, 12602-810 Lorena - SP, Brasil

Recebido em 29/11/08; aceito em 8/4/09; publicado na web em 22/9/09

\begin{abstract}
A VISION OF WOOD STRUCTURE, COMPOSITION AND BIODEGRADATION. Wood is the main raw material used in the pulp and paper industry. It is a material that presents heterogeneous structure and complex composition, which results in a relatively resistant material to the biodegradation process. In the present review, we attempted to summarize the structural characteristics of wood and describe the chemical nature of its major components to, afterwards, comment about its biodegradation. The role of the enzyme manganese peroxidase in the lignin degradation by a selective white-rot fungus, Ceriporiopsis subvermispora, was highlighted.
\end{abstract}

Keywords: cellulose; hemicellulose; lignin.

\section{MADEIRA: ESTRUTURA E COMPOSIÇÃO QUÍMICA}

A madeira é um material heterogêneo. Basicamente, é constituída por tecidos formados por células com paredes celulares espessas, cujas formas e tamanhos variam de acordo com a espécie. A integridade estrutural destes tecidos é atribuída à lamela média, uma camada que mantém as células adjacentes unidas entre si. ${ }^{1,2}$

De maneira geral, as madeiras podem ser agrupadas em duas categorias distintas: "moles" (softwoods) e "duras" (hardwoods). As madeiras moles, ou de coníferas, pertencem ao grupo das gimnospermas, que apresenta como características distintivas a folhagem na forma de agulha e a ausência de frutos (sementes descobertas). As madeiras duras, ou de folhosas, pertencem ao grupo das angiospermas dicotiledôneas, que apresenta como características distintivas folhas largas e sementes encerradas em frutos. ${ }^{1}$

Nas madeiras de coníferas, as células que servem ao transporte de água e nutrientes também provêem suporte mecânico. Por outro lado, as madeiras de folhosas apresentam células especializadas específicas para cada uma destas funções. ${ }^{2}$

Conforme pode ser observado na Figura 1, em termos estruturais as madeiras de coníferas são relativamente simples, sendo compostas quase que totalmente por um único tipo de células alongadas (2-5 mm) denominadas traqueídeos. Células transversais que compõem o raio e canais de resina também são encontrados. ${ }^{1,3}$ As madeiras de folhosas, por sua vez, são estruturalmente mais complexas e apresentam maior diversidade de padrões de organização celular. Três tipos básicos de células são encontrados nesta categoria: aquelas que compõem os vasos, as fibras e as células do raio, que constituem o parênquima radial. As células dos vasos (0,2-0,5 mm de comprimento) e as fibras (1,0-2,0 mm de comprimento) são as encontradas em maior quantidade.,

Em termos de ultraestrutura, a parede de cada célula é formada por diversas camadas: parede primária $(\mathrm{P})$, parede secundária externa (S1), parede secundária média (S2) e parede secundária interna (S3) (Figura 2). Estas camadas são compostas por microfibrilas celulósicas orientadas no espaço de forma definida, dependendo da camada. ${ }^{2}$

Conforme pode ser observado na Figura 3, várias moléculas de glucose unem-se através de ligações glicosídicas do tipo $\beta(1 \rightarrow 4)$ formando cadeias lineares que interagem umas com as outras através de ligações de hidrogênio. A estrutura resultante, denominada fibrila elementar, é insolúvel em água e apresenta alto grau de cristalinidade.

*e-mail: carvalho@ debiq.eel.usp.br
Quatro fibrilas elementares são então agrupadas por uma monocamada de hemicelulose, sendo posteriormente circundadas em uma matriz de hemicelulose e lignina (associadas entre si por meio de interações físicas e ligações covalentes). O compósito natural resultante desta íntima associação é denominado microfibrila celulósica. ${ }^{2,5}$

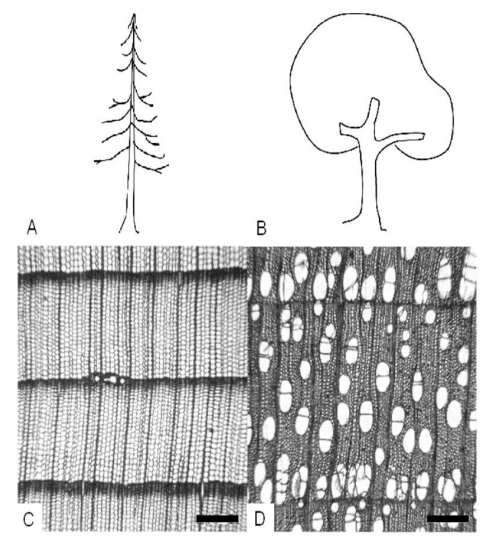

Figura 1. Representação esquemática de uma madeira de conífera (A); representação esquemática de uma madeira de folhosa (B); micrografia da seção transversal do tronco de uma madeira de conífera (C); micrografia da seção transversal do tronco de uma madeira de folhosa (D). Barras de escala com comprimento de $300 \mu$ m. Adaptada da ref. 1

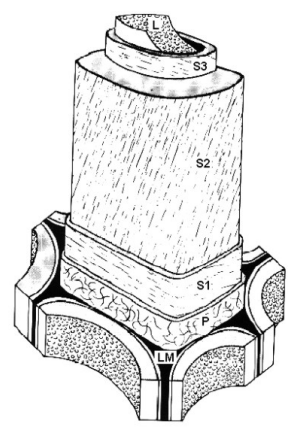

Figura 2. Representação esquemática de uma célula vegetal: lamela média $(L M)$; parede primária $(P)$; parede secundária externa $(S 1)$; parede secundária média (S2); parede secundária interna (S3); lúmen (L). Adaptada da ref. 2 
Em termos de composição química, a parede celular vegetal é constituída por celulose, hemicelulose e lignina. ${ }^{1-4}$

A celulose é um homopolissacarídeo linear constituído unicamente por moléculas de glucose unidas entre si através de ligações glicosídicas do tipo $\beta(1 \rightarrow 4)$, que resultam da perda de uma molécula de água. ${ }^{2}$

O termo hemicelulose é utilizado coletivamente para denominar grupos distintos de polissacarídeos constituídos por açúcares pentoses (xilose e arabinose) e/ou hexoses (glucose, manose e galactose), ácidos urônicos e grupos acetila. ${ }^{2} \mathrm{Em}$ geral, enquanto as madeiras de folhosas são compostas principalmente por heteroxilanas altamente acetiladas, as madeiras de coníferas apresentam uma elevada proporção de glucomananas e galactoglucomananas parcialmente acetiladas. ${ }^{5}$

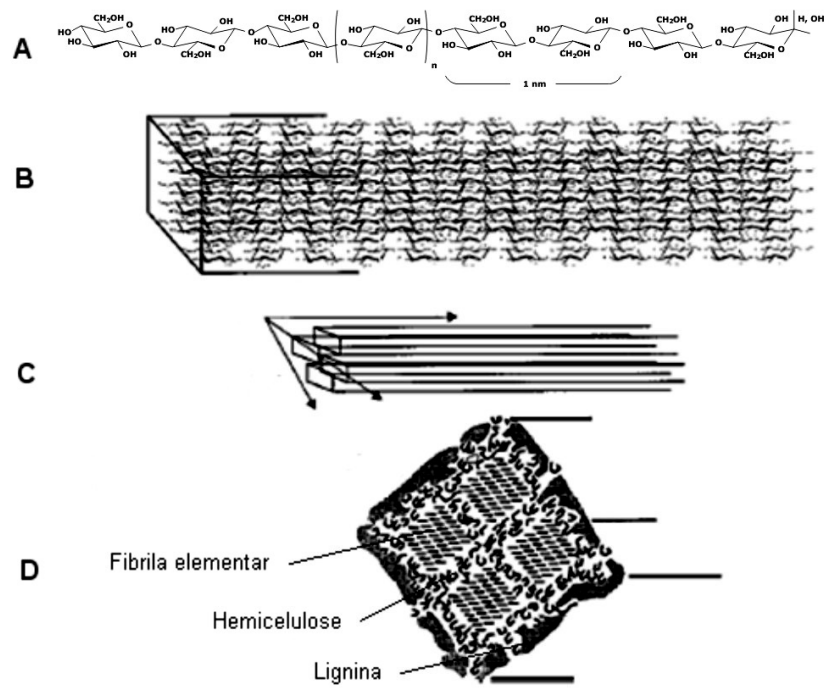

Figura 3. Representação esquemática das associações químicas que ocorrem na parede celular vegetal: ligações entre moléculas de glucose (A) e interações entre as cadeias lineares adjacentes para a formação da fibrila elementar $(B)$; associação entre quatro fibrilas elementares adjacentes $(C)$, hemicelulose e lignina para a formação da microfibrila celulósica (D). Adaptada da ref. 5

A lignina, por sua vez, é uma macromolécula sintetizada por via radicalar a partir de três álcoois p-hidróxi-cinamílicos precursores: $p$-cumarílico, coniferílico e sinapílico. Dependendo do grau de metoxilação do anel aromático, diz-se que a unidade básica é $p$-hidróxifenil (não metoxilada, derivada do álcool $p$-cumarílico), guaiacil (com uma metoxila, derivada do álcool coniferílico) ou siringil (com duas metoxilas, derivada do álcool sinapílico). ${ }^{2}$ Enquanto as ligninas de madeiras de coníferas são compostas quase que exclusivamente por unidades guaiacil, sendo denominadas de ligninas tipo $\mathrm{G}$, as ligninas de madeiras de folhosas são mais ricas em unidades siringil, sendo denominadas de ligninas tipo GS. ${ }^{2}$

A Figura 4 ilustra os vários tipos de acoplamento que podem ocorrer entre as unidades básicas que constituem a lignina, dando origem a ligações como $\beta$-O-4 e $\alpha-\mathrm{O}-4$ (50-65\%), $\beta-1$ (9-15\%), $\beta-5$ (6-15\%), 5-5 (2-9\%) e $\beta-\beta(2-5 \%) .{ }^{6}$ Mais recentemente, estruturas do tipo dibenzodioxocinas, que compreendem um acoplamento múltiplo entre 3 fragmentos fenil-propano via ligações 5-5, $\beta$-O-4 e $\alpha$-O-4, têm sido descritas como formadoras de partes expressivas da estrutura desta macromolécula. ${ }^{7}$

Na última década, muitos estudos referentes à manipulação das vias de biossíntese da lignina têm sido realizados, pois há enorme interesse dentro do tema devido à possibilidade de se obter plantas mais adequadas aos processos de deslignificação usados na indústria de celulose e papel, bem como à nascente indústria de conversão da biomassa lignificada em etanol. ${ }^{8,9}$

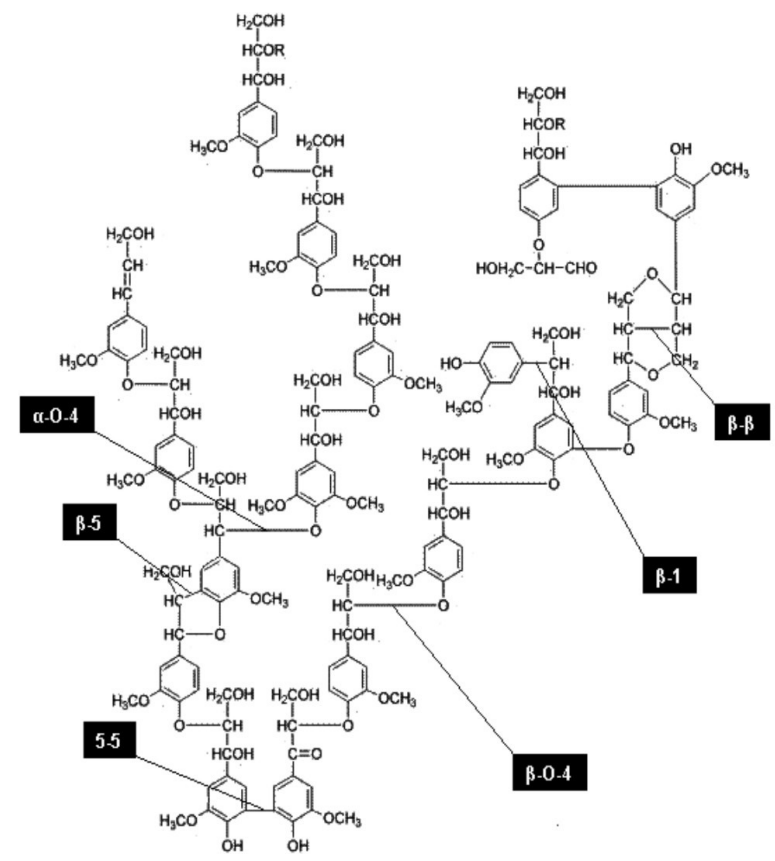

Figura 4. Principais tipos de ligações entre as unidades básicas que constituem a lignina (lignina tipo G). Adaptada da ref. 6

A proporção entre os componentes da parede celular (celulose, hemicelulose e lignina) depende da espécie vegetal e varia de camada para camada. Em geral, o teor de lignina encontrado em madeiras de coníferas (25-35\%) é superior àquele encontrado em madeiras de folhosas (18-25\%). Por outro lado, enquanto a lignina responde por até $84 \%$ do peso da lamela média composta $(\mathrm{LM}+\mathrm{P})$, a parede secundária interna (S3) é constituída por até $87 \%$ de hemicelulose, com pouca ou nenhuma lignina. A parede secundária média (S2), usualmente mais espessa que as demais, apresenta em média $54 \%$ de celulose. ${ }^{1}$

Neste ponto, é importante diferenciar os componentes da parede celular, polissacarídeos e lignina, daqueles compostos estranhos à fibra vegetal, os quais não são considerados essenciais à estrutura da parede celular ou da lamela média. Muitos destes últimos componentes são prontamente solúveis em água ou solventes orgânicos neutros, razão pela qual são coletivamente denominados extraíveis. Outros, como proteínas e sais de ácidos inorgânicos, por outro lado, podem ser completamente insolúveis nos solventes utilizados para a remoção dos extraíveis. ${ }^{10}$

Frequentemente associados a propriedades como cor, cheiro e sabor, os extraíveis são constituídos por substâncias de baixa massa molar envolvidas no metabolismo da planta. Quimicamente, consistem em açúcares, compostos aromáticos, ceras, ácidos graxos e resinas (terpenos, lignanas, estilbenos, flavonoides), entre outros. Em geral, perfazem de 2 a $8 \%$ da massa total em base seca, sendo os teores encontrados em folhosas geralmente superiores àqueles presentes em coníferas. ${ }^{5,11}$ Estes compostos desempenham um papel importante no processo de biodegradação da madeira, pois podem atuar como mediadores que fomentam a redução de íons metálicos como o $\mathrm{Fe}^{3+12} \mathrm{e}$ a atividade de enzimas como a manganês peroxidase.$^{13}$ Por outro lado, também podem atuar como protetores da madeira contra o ataque de micro-organismos, devido à atividade antimicrobiana exibida por vários de seus constituintes. ${ }^{14,15}$

\section{BIODEGRADAÇÃO DA MADEIRA}

Na natureza, os micro-organismos mais eficientes na biodegradação da madeira são os fungos decompositores da madeira. ${ }^{2}$

A biodegradação inicia-se com a penetração da hifa fúngica através do lúmen da célula vegetal. Para se estabelecer, o fungo promove 
uma intensa secreção de metabólitos extracelulares, especialmente enzimas, que levam à conversão dos componentes da parede celular vegetal (celulose, hemicelulose e lignina) em moléculas menores, as quais podem ser transportadas através da membrana plasmática fúngica e adentrar o metabolismo intracelular. ${ }^{16}$

Os fungos decompositores da madeira podem ser classificados em três grupos: fungos de decomposição branca (white-rot fungi), capazes de degradar os três componentes da parede celular vegetal (celulose, hemicelulose e lignina); fungos de decomposição parda (brown-rot fungi), capazes de degradar principalmente as frações polissacarídicas (celulose e hemicelulose) e, fungos de decomposição branda (soft-rot fungi), que podem degradar tanto os polissacarídeos quanto a lignina, porém em velocidades muito reduzidas. ${ }^{16}$

Entre os fungos de decomposição branca, considerados os mais eficientes na biodegradação da madeira, existem aqueles que promovem ataque erosivo e aqueles que promovem ataque não erosivo à parede celular vegetal. $\mathrm{O}$ ataque erosivo caracteriza-se pela remoção simultânea de celulose, hemicelulose e lignina. Já o ataque não erosivo caracteriza-se pela manutenção da celulose à custa da degradação de hemicelulose e lignina. ${ }^{16}$

Conforme ilustrado na Figura 5, a hidrólise completa da celulose requer a ação combinada de pelo menos três grupos de enzimas que atuam em sinergia: endoglucanases (EC 3.2.1.21), que hidrolisam ligações glicosídicas no interior da cadeia, principalmente nas regiões amorfas, liberando fragmentos menores; celobio-hidrolases (EC 3.2.1.91), que hidrolisam ligações glicosídicas nas extremidades da cadeia, liberando dímeros de glucose (celobioses) e, $\beta$-glucosidases (EC 3.2.1.21), que hidrolisam as celobioses, liberando unidades de glucose. ${ }^{17}$ Além destas, outras proteínas como as expansinas ${ }^{18}$ e as swoleninas ${ }^{19}$ têm sido reportadas como capazes de afrouxar a estrutura da celulose cristalina, o que favorece a sua sacarificação.

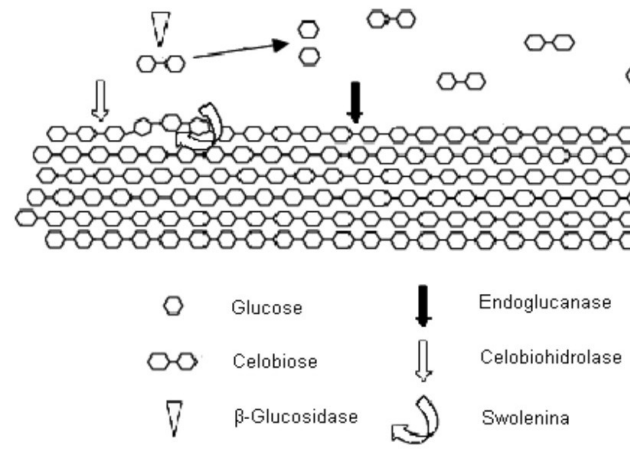

Figura 5. Sistema enzimático envolvido na degradação da celulose. Adaptada da ref. 17

Por outro lado, conforme ilustrado na Figura 6, a hidrólise enzimática da hemicelulose ocorre pela ação combinada de diversas endoenzimas, exoenzimas e enzimas auxiliares. Por exemplo, a hidrólise da xilana envolve a ação de pelo menos dois grupos de enzimas, endo 1,4- $\beta$-D-xilanases (EC 3.2.1.8) e $\beta$-D-xilosidases (EC 3.2.1.37), atuando na cadeia principal. Dependendo do tipo de xilana, podem ser também necessárias enzimas auxiliares para a clivagem das cadeias laterais, como $\alpha$-D-glucuronidases (EC 3.2.1.131) e acetil-xilana-esterases (EC 3.1.1.72) entre outras. ${ }^{17}$

Por sua vez, as enzimas envolvidas na degradação da lignina podem ser agrupadas em duas classes distintas: fenoloxidases e, enzimas que produzem peróxido de hidrogênio. Entre as fenoloxidases, pode-se ainda identificar dois subgrupos: enzimas dependentes de peróxido (lignina peroxidases e manganês peroxidases) e, enzimas não-dependentes de peróxido (lacases). ${ }^{16}$

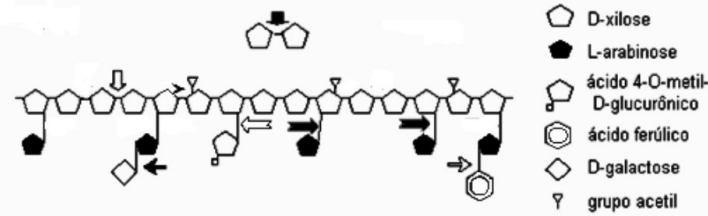

\begin{tabular}{|c|c|c|}
\hline Enzima & Simbolo & Ligaçĩo hidrolissda \\
\hline Endo-1,4- $\beta$-xilanase & II & $\beta-(1-4)$ \\
\hline$\beta$-D-xilosidase & $=$ & $\beta-(1-4)$ \\
\hline Arabino-furano-hidrolase & $\Rightarrow$ & $\alpha-L-(1-2), \alpha-L-(1-3), \alpha-L-(1-5)$ \\
\hline a-D-glucuronidase & $\Leftrightarrow$ & $\alpha-(1-2)$ \\
\hline Feruloil-esterase & $\Rightarrow$ & Éster \\
\hline a-D-galactosidase & $\leftarrow$ & $\alpha-(1-6)$ \\
\hline Acetil-xilana-esterase & $>$ & Éster \\
\hline
\end{tabular}

Figura 6. Sistema enzimático envolvido na degradação da hemicelulose (arabinoxilana). Adaptada da ref. 17

As lacases (Lacs) e as manganês peroxidases (MnPs) apresentam potencial de redução suficiente para abstrair elétrons somente de estruturas fenólicas, embora na presença de mediadores apropriados sua ação possa ser estendida também para estruturas não fenólicas..$^{20,21}$ As lignina peroxidases (LiPs), por apresentarem potencial de redução maior que as Lacs e MnPs, podem oxidar diretamente estruturas aromáticas não fenólicas, ${ }^{22}$ embora possam também exercer sua ação catalítica por meio de mediadores de baixa massa molar. ${ }^{23}$

As enzimas que produzem peróxido são acessórias às peroxidases, gerando peróxido de hidrogênio in situ e possibilitando que as peroxidases atuem. Entre as principais enzimas produtoras de peróxido descritas na literatura encontram-se: intracelulares - glucose oxidase e metanol oxidase ${ }^{16}$ e extracelulares - glioxal oxidase ${ }^{24}$ e aril-álcool oxidase. ${ }^{25}$

Uma enzima que até pouco tempo atrás era associada somente ao complexo celulolítico, celobiose desidrogenase, aparentemente coliga os sistemas hidrolítico e oxidativo. Ela pode oxidar oligossacarídeos e, em seguida, transferir os elétrons para aceptores como quinonas, $\mathrm{Fe}^{+3}$ e $\mathrm{O}_{2} \cdot{ }^{26,27}$

Tanto as celulases quanto as hemicelulases são hidrolases que apresentam uma especificidade muito grande pelos respectivos substratos. Desta forma, estas enzimas têm sua ação limitada pela necessidade de contato direto com os polissacarídeos que constituem a parede celular vegetal. ${ }^{16}$

Ao contrário, as enzimas relacionadas com a biodegradação da lignina são oxidases inespecíficas que podem exercer sua ação catalítica por meio de mediadores de baixa massa molar. ${ }^{16}$ Tal modo de ação permite explicar, pelo menos em parte, como os fungos seletivos na decomposição da lignina conseguem promover alterações não erosivas ao longo da parede celular vegetal antes mesmo que esta se torne permeável às enzimas envolvidas na ligninólise. Pequenos o suficiente para penetrar no complexo da parede celular vegetal, estes compostos seriam capazes de degradar os componentes à distância e, com isto, desestruturar a parede celular a ponto de, então, permitir a penetração de enzimas oxidativas e hidrolíticas. ${ }^{28}$

Nos últimos anos, a utilização de fungos de decomposição branca seletivos na degradação de lignina tem sido proposta como um prétratamento para a obtenção de polpas celulósicas. Na prática, esta estratégia é denominada biopolpação e consiste em submeter os cavacos de madeira à biodegradação por um fungo seletivo na degradação de lignina previamente à polpação propriamente dita. ${ }^{29,30} \mathrm{Em}$ geral, o pré-tratamento biológico, mesmo quando conduzido por intervalos relativamente curtos (de até 30 dias), aumenta a susceptibilidade da lignina à solubilização pelos licores de polpação (no caso de processos químicos) e facilita o desfibramento e refino da polpa (no caso de processos mecânicos), resultando em economia de reagentes e/ou energia. ${ }^{29,31}$ 
Entre os fungos que apresentam seletividade na degradação da lignina, grande atenção tem sido direcionada para o basidiomiceto Ceriporiopsis subvermispora, um fungo selecionado de forma empírica e cuja aplicação em escala industrial já foi demonstrada com êxito. ${ }^{32}$ Em termos microscópicos, esse fungo ataca a parede celular vegetal de forma não erosiva, causando a remoção de extraíveis, lignina e hemicelulose de forma progressiva no sentido lúmen $\rightarrow$ lamela média sem solubilizar quantidades apreciáveis de celulose nos estágios iniciais da biodegradação. ${ }^{33}$

Diversos estudos têm sido conduzidos para compreender os mecanismos químicos e bioquímicos envolvidos na biodegradação da madeira por C. subvermispora ${ }^{12,34-42}$ Em termos de enzimas, sabe-se que, entre as hidrolases, este fungo produz um complexo celulolítico deficiente em celobio-hidrolases e um complexo hemicelulolítico com atividade expressiva de xilanases. ${ }^{43,44}$ Com relação às oxidases, assume-se que as principais enzimas produzidas por $C$. subvermispora são MnPs e Lacs, ${ }^{36,38,45}$ pois, embora genes semelhantes aos que codificam LiPs em outros fungos tenham sido identificados em C. subvermispora ${ }^{46}$ a presença de atividade desta enzima ainda não foi detectada em cultivos deste fungo. Um fato importante a ser considerado é a não detecção de atividade de Lacs em quantidades significativas quando o fungo é cultivado em cavacos de madeira sob condições que simulam o processo industrial. Nestas condições, a biodegradação de lignina por $C$. subvermispora parece se dever principalmente à ação de MnPs. ${ }^{40,47}$

O ciclo catalítico das MnPs inicia-se com a sua oxidação por $\mathrm{H}_{2} \mathrm{O}_{2}$ ou peróxidos orgânicos, que levam a enzima nativa a um estado de oxidação deficiente em dois elétrons, denominado composto I. Conforme ilustrado na Figura 7, a redução da enzima até a forma nativa ocorre através de dois passos sucessivos, por meio da formação de um intermediário denominado composto II. Enquanto o composto I pode ser convertido em composto II tanto na presença de $\mathrm{Mn}^{2+}$ quanto de outros doadores de elétrons com potencial redox apropriado, a conversão do composto II até a enzima nativa ocorre somente na presença de $\mathrm{Mn}^{2+} .{ }^{48,49}$

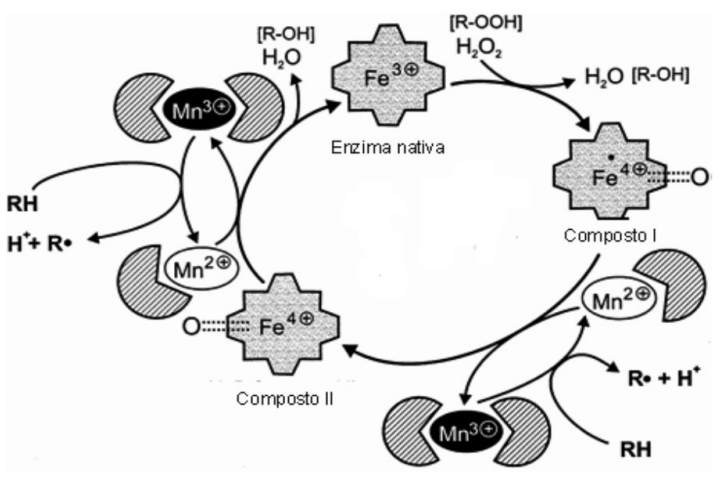

Figura 7. Ciclo catalítico de manganês peroxidases. Adaptada da ref. 49

$\mathrm{O} \mathrm{Mn}^{3+}$ formado durante a catálise, estabilizado por ácidos orgânicos produzidos pelo próprio fungo, ${ }^{36}$ pode abstrair elétrons de vários compostos orgânicos (incluindo fenois, aminas aromáticas, compostos sulfurados e ácidos graxos insaturados) de maneira inespecífica, levando à formação de radicais bastante reativos (Figura 8) que podem atacar estruturas recalcitrantes com alto potencial de redução. ${ }^{49,50}$ Os quelatos supramencionados podem inclusive levar à formação de superóxido, o qual se acredita ser uma fonte de peróxidos na ausência de $\mathrm{H}_{2} \mathrm{O}_{2} \cdot{ }^{51}$

Assim, postula-se que as alterações observadas na parede celular vegetal durante os estágios iniciais de biodegradação da madeira pelo basidiomiceto $C$. subvermispora sejam devidas à ação de mediadores de baixa massa molar, principalmente o íon $\mathrm{Mn}^{3+}$. Esse íon seria responsável pela oxidação direta de subestruturas fenólicas ${ }^{51}$ e pela iniciação da peroxidação de ácidos graxos insaturados, que levam à formação de radicais organo-peroxila, que, por sua vez, oxidam subestruturas não-fenólicas. ${ }^{52}$

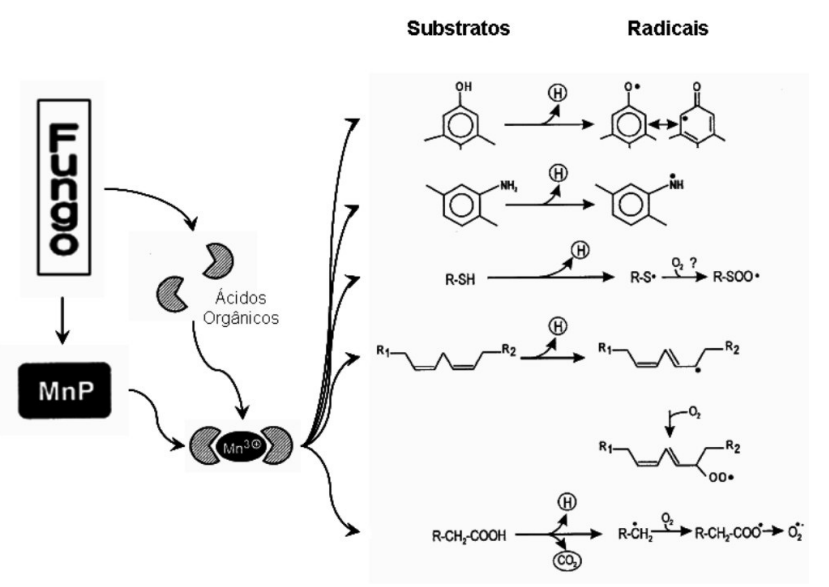

Figura 8. Formação de radicais pelo sistema catalítico de manganês peroxidases na presença de diferentes substratos. Adaptada da ref. 49

\section{CONCLUSÃO}

A biodegradação da madeira consiste em um processo complexo no qual múltiplas enzimas devem atuar cooperativamente, algumas delas tendo ação mediada por moléculas de baixa massa molar. Certas espécies de fungos secretam todos esses complexos enzimáticos, ou parte deles, além de mediadores de baixa massa molar. Devido à heterogeneidade composicional e estrutural dos substratos lignificados e à diversidade de vias catalíticas apresentada por diferentes espécies de fungos degradadores desses materiais, está claro que não há um modelo bioquímico único capaz de explicar a biotransformação dos componentes da parede celular vegetal. No caso específico do fungo $C$. subvermispora, pode-se concluir que a sua ação sobre a parede celular lignificada segue o modelo não erosivo e isso se deve à capacidade do fungo de secretar MnPs e ácidos orgânicos aptos a transportar os íons manganês, além de hemicelulases. Por outro lado, o fungo não secreta quantidades apreciáveis de celobio-hidrolases, o que justifica a ação limitada sobre a celulose. A estruturação de modelos bioquímicos mais abrangentes, envolvendo uma diversidade maior de espécies fúngicas, certamente abriria as portas para novas aplicações industriais, constituindo-se, portanto, em um tema atrativo para pesquisa e desenvolvimento. Neste contexto, o leitor é direcionado para um outro artigo de revisão publicado recentemente, ${ }^{30}$ onde os autores detalham um estudo continuado que visou entender um caso particular de biodegradação da madeira.

\section{AGRADECIMENTOS}

Aos auxílios financeiros recebidos da FAPESP, do CNPq e da CAPES.

\section{REFERÊNCIAS}

1. Rowell, R. M.; Handbook of Wood Chemistry and Wood Composites, $1^{\text {st }}$ ed., CRC Press: Madison, 2005.

2. Fengel, D.; Wegener, G.; Wood Chemistry, Ultrastructure and Reactions, $1^{\text {st }}$ ed., Walter de Gruyter: Berlin, 1989. 
3. Walker, J. C. F.; Butterfield, B. G.; Langrish, T. A. G.; Harris, J. M.; Uprichard, J. M.; Primary Wood Processing, $1^{\text {st }}$ ed., Chapman and Hall: London, 1993.

4. Desch, H. E.; Dinwoodie, J. M.; Timber: Structure, properties, conversion and use, $7^{\text {th }}$ ed., MacMillan Press: London, 1996.

5. Ramos, L. P.; Quim. Nova 2003, 26, 863.

6. Adler, E.; Wood Sci. Technol. 1977, 11, 169.

7. Ralph, J.; Lundquist, K.; Brunow, G.; Lu, F.; Kim, H.; Schatz, P. F.; Marita, J. M.; Hatfield, R. D.; Ralph, S. A.; Christensen, J. H.; Boerjan, W.; Phytochem. Rev. 2004, 3, 298.

8. Boerjan, W.; Ralph, J.; Baucher, M.; Annu. Rev. Plant Biol. 2003, 54, 519.

9. Vanholme, R.; Morreel, K.; Ralph, J.; Boerjan, W.; Curr. Opin. Plant Biol. 2008, 11, 278 .

10. Browning, B. L.; Methods of Wood Chemistry, $1^{\text {st }}$ ed., John Wiley \& Sons: New York, 1967.

11. Philipp, P.; D’Almeida, M. L. O.; Celulose e papel: Tecnologia de fabricação da pasta celulósica, $2^{\mathrm{a}}$ ed., IPT: São Paulo, 1988.

12. Aguiar, A.; Ferraz, A.; Int. Biodeterior. Biodegrad. 2008, 61, 182.

13. Hofrichter, M.; Lundell, T.; Hatakka, A.; Appl. Environ. Microbiol. 2001, 67,4588 .

14. Haupt, M.; Leithoff, H.; Meier, D.; Puls, J.; Richter, H. G.; Faix, O.; Holz als Roh- und Werkst. 2003, 61, 473.

15. Venalainen, M.; Harju, A. M.; Saranpaa, P.; Kainulainen, P.; Tiitta, M.; Velling, P.; Wood Sci. Technol. 2004, 38, 109.

16. Kirk, T. K.; Cullen, D. Em Environmentally Friendly Technologies for the Pulp and Paper Industry; Young, R.; Akhtar, M., eds.; John Wiley \& Sons: New York, 1998, cap. 9.

17. Aro, N.; Pakula, T.; Penttila, M.; FEMS Microbiol. Rev. 2005, 29, 719.

18. Mason, M. S.; Durachko, D. M.; Cosgrove, D. J.; Plant Cell. 1992, 4, 1425.

19. Saloheimo, M.; Paloheimo, M.; Hakola, S.; Pere, J.; Swanson, B.; Nyyssonen, E.; Bhatia, A.; Ward, M.; Penttila, M.; Eur. J. Biochem. 2002, $269,4202$.

20. Bourbonnais, R.; Paice, M. G.; FEBS Lett. 1990, 267, 99.

21. Bao, W.; Fukushima, Y.; Jensen, K. A.; Moen, M. A.; Hammel, K. E.; FEBS Lett. 1994, 354, 297.

22. Kirk, T. K.; Farrel, R. L.; Annu. Rev. Microbiol. 1987, 41, 465.

23. Tien, M.; Ma, D.; J. Biol. Chem. 1997, 272, 8912.

24. Kersten, P. J.; Kirk, T. K.; J. Bacteriol. 1978, 169, 2195.

25. Ander, P.; Marzullo, L.; J. Biotechnol. 1997, 53, 115.

26. Henriksson, G.; Johansson, G.; Pettersson, G.; J. Biotechnol. 2000, 78, 93.

27. Have, R.; Teunissen, P. J. M.; Chem. Rev. 2001, 101, 3397.

28. Blanchette, R. A.; Krueger, E. W.; Haight, J. E.; Akhtar, M. E.; Akin, D. E.; J. Biotechnol. 1997, 53, 203.
29. Akhtar, M.; Blanchette, R. A.; Myers, G. E.; Kirk, K. Em ref. 16, cap. 10.

30. Ferraz, A.; Guerra, A.; Mendonça, R.; Masarin, F.; Vicentim, M. P.; Aguiar, A.; Pavan, P. C.; Enzyme Microb. Technol. 2008, 43, 178.

31. Ferraz, A.; Christov, L.; Akhtar, M. Em ref. 16, cap. 13.

32. Akhtar, M.; Scott, G. M.; Swaney, R. E.; Shipley, D. F.; Resour. Conserv. Recycl. 2000, 28, 241 .

33. Mendonça, R.; Ferraz, A.; Kordsachia, O.; Koch, G.; Wood Sci. Technol. 2004, 38, 567.

34. Rahmawati, N.; Ohashi, Y.; Watanabe, T.; Honda, Y.; Watanabe, T.; Biomacromolecules 2005, 6, 2851.

35. Milagres, A. M. F.; Magalhães, P. O.; Ferraz, A.; FEMS Microbiol. Lett. 2005, 253, 267

36. Aguiar, A.; Cruz, P. B. S.; Ferraz, A.; Enzyme Microb. Technol. 2006, 38,873 .

37. Fackler, K.; Gradinger, C.; Hinterstoisser, B.; Messner, K.; Schwanninger, M.; Enzyme Microb. Technol. 2006, 39, 1476.

38. Vicentim, M. P.; Ferraz, A.; Enzyme Microb. Technol. 2007, 40, 645

39. Chi, Y.; Hatakka, A.; Maijala, P.; Int. Biodeterior. Biodegrad. 2007, 59, 32.

40. Carvalho, W.; Ferraz, A.; Milagres, A. M. F.; Enzyme Microb. Technol. 2008, 43, 193 .

41. Alvarez, J. M.; Canessa, P.; Mancilla, R. A.; Polanco, R.; Santibáñez, P. A.; Vicuña, R.; Fungal Genet. Biol. 2009, 46, 104.

42. Magalhães, P. O.; Milagres, A. M. F.; Int. Biodeterior. Biodegrad. 2009, $63,191$.

43. Sethuraman, A.; Akin, D. E.; Eriksson, K. E. L.; Biotechnol. Appl. Biochem. 1998, 27, 337.

44. Heidorne, F. O.; Magalhães, P. O.; Ferraz, A. L.; Milagres, A. M. F.; Enzyme Microb. Technol. 2006, 38, 436.

45. Ferraz, A.; Córdova, A. M.; Machuca, A.; Enzyme Microb. Technol. 2003, 32, 59.

46. Rajakumar, S.; Gaskell, J.; Cullen, D.; Lobos, S.; Vicuña, R.; Appl. Environ. Microbiol. 1996, 62, 2660.

47. Ferraz, A.; Guerra, A.; Cruz, P. B. S.; Mendonça, R. Em Biotechnology in the Pulp and Paper Industry; Huilgol, R. R.; Viikari, L.; Lantto, R., eds.; Elsevier: New York, 2002, cap. 8.

48. Wariishi, H.; Akaleswaran, L.; Gold, M. H; Biochem. 1988, 27, 5365.

49. Hofrichter, M.; Enzyme Microb. Technol. 2002, 30, 454.

50. Kawai, S.; Jensen, K. A.; Bao, W.; Hammel, K. E.; Appl. Environ. Microbiol. 1995, 61, 3407.

51. Urzua, U.; Kersten, P. J.; Vicuña, R.; Arch. Biochem. Biophys. 1998, 360, 215.

52. Kapich, A. N.; Jensen, K. A.; Hammel, K. E.; FEBS Lett. 1999, 461, 115. 